\title{
A Little Lie Never Hurt Anyone: Attitudes toward Various Types of Lies over the Lifespan
}

\author{
Monica Buta ${ }^{\mathrm{a}}$, George Visu-Petra ${ }^{\mathrm{a}, \mathrm{b}}$, Silvia H. Koller ${ }^{\mathrm{c}}$, Laura Visu-Petra ${ }^{\mathrm{a}^{*}}$ \\ ${ }^{a}$ Research in Individual Differences and Legal Psychology (RIDDLE) Lab, \\ Department of Psychology, Babeș-Bolyai University, Cluj-Napoca, Romania \\ ${ }^{\mathrm{b}}$ Court of Appeal, Cluj-Napoca, Romania \\ ${ }^{c}$ Federal University of Rio Grande, Porto Alegre, Brasil \\ *Corresponding author. E-mail: laurapetra@psychology.ro
}

Background. A growing body of evidence shows that people's attitudes toward lies could be predictive of their actual deceptive behavior. However, few studies have examined both attitudes and deceptive behavior, and none have related attitudes toward the likelihood of self-reported deception as it develops over people's lifespans.

Objective. Our study addresses attitudes toward lies and the likelihood of deceptive behavior in a variety of contexts, relating them to self-reported frequency of lying. We were also interested in whether individual differences in social desirability and social anxiety predict self-reported frequency of lying across lifespans.

Design. Using a cross-sectional design that included children as well as young adults, we assessed a total of 177 participants with the same questionnaire about deception, adapted from Lundquist et al. (2009).

Results. The age differences in the frequency of self-reported lying followed an inverted U-shape trend over time. Children's lower social desirability and more lenient attitudes toward white lies predicted higher lying frequency, whereas for adults, a greater likelihood of telling prosocial lies predicted higher lying frequency. Children with decreased anxiety were less likely to tell prosocial lies, implying that anxiety might be a key factor in children's development of deception.

Conclusion. Our work offers an integrative view into people's attitudes towards deception and their self-reported lying as they mature. Attitudes toward white lies and the self-reported likelihood of telling prosocial lies were the most relevant predictors involved in self-reported lie-telling. Individual differences in anxiety and social desirability also played a relevant role in children's and young adults' attitudes toward deception.

Keywords: attitudes; deception; lying frequency; anxiety; social desirability; prosocial lies; white lies 


\section{Introduction}

Lying is viewed as reprehensible and undesirable; yet it is acknowledged as necessary and acceptable under certain circumstances. Recent findings associated people's higher acceptance of lying with increases in their deceptive behavior (Halevy, Shalvi \& Verschuere, 2014; McLeod \& Genereaux, 2008). Deceptive behavior emerges during preschool years, as children tell simple lies to avoid punishment or gain benefits. As they grow, children show more advanced self-interested lying skills, but they also begin to produce prosocial lies, a process complementary to their being socialized to tell the truth (Popliger, Talwar, \& Crossman, 2011).

Young children view all false statements as lies and rate them negatively. But during middle childhood, false statements told to help others are no longer viewed as lies (Bussey, 1999), with older children consistently rating prosocial lies more positively than antisocial ones (Bussey, 1999; Lavoie, Nagar, \& Talwar, 2017; Popliger et al., 2011; Talwar, Williams, Renaud, Arruda, \& Saykaly, 2016). Moreover, adolescents accept prosocial lies more than lies related to self-gain or revenge (Jensen, Arnett, Feldman, \& Cauffman, 2004).

Significant information about the acceptance of lying among adults comes from studies on economic behavior. Lundquist et al. (2009) were interested in people's aversion to lying. They examined attitudes about white lies (defined as small lies that benefit the sender and receiver), and whether or not people believed there are degrees of lying (as opposed to believing that a statement is either a lie or a truth, with no middle ground). They also investigated whether the self-reported likelihood of lying varied across various types of lies, (i.e., prosocial and self-interested lies). Lundquist and his collaborators showed that individuals are less inclined to lie when they risk discovery, or when they had promised to tell the truth, and that aversion to lying increases with the strength of their truth promise.

As far as lying frequency was concerned, several studies indicated the people lie once or twice a day; however, their data was skewed by a very high number of lies being told by a very small number of prolific liars in the sample (Serota, Levine, \& Boster, 2010; Serota, Levine, \& Burns, 2012). The development of lying across the lifespan follows an inverted U-shape (Debey et al., 2015; Lavoie et al., 2017; Maggian \& Villeval, 2013). Children show a gradually increasing propensity to lie as they grow older (Lavoie et al., 2017; Talwar et al., 2007). Adolescents report a higher lying frequency than undergraduates or adults (Levine et al., 2013), and young adults lie more often than older adults (DePaulo et al.,1996), suggesting that lying develops in childhood, reaches a maximum in adolescence, and then declines into adulthood. However, other studies showed that lying decreases as children grow (Glätzle-Rützler \& Lergetporer, 2015; Maggian \& Villeval, 2013). These studies used experimental tasks that resemble economic games, which differ from the common everyday deception scenarios that children encounter.

Most studies examined attitudes toward deception and lying frequency separately, therefore yielding little about their relationship. Children's moral evaluations and understanding of hypothetical deceptive scenarios are related to their lying behavior (Popliger et al., 2011; Talwar \& Lee, 2008). Adults who lie frequently tend to view deception less negatively, their attitudes toward lies being linked to the frequency of deceptive behavior (Brasher, Lee, Shather, \& Mou, 2014; Halevy et 
al., 2014). The evidence indicates a connection between attitudes and behavior; yet little is known about the direction of this link and how it may change as people advance in age.

Regarding gender differences: among children, boys appear to tell more lies and be more accepting of deception (Goosie, 2014; Jensen, et al., 2004). In adulthood, gender effects are less straightforward. Ning and Crossman (2007) showed that women rated lies more positively than men did, whereas Levine et al. (1992) found that men displayed greater acceptance of lying than women. More recently, however, Oliveira and Levine (2008) failed to reproduce these results, and found no reliable gender differences in lie acceptance.

Anxiety also plays a role in deception. Low anxiety was linked with high lying scores (Eswara \& Suryarekha, 1974), and individuals often report anxiety, guilt, and an increased cognitive load when telling a lie (Caso, Gnisci, Vrij, \& Mann, 2005; Gozna, Vrij, \& Bull, 2001).

Since lying is essentially a social interaction process, we would expect people who are more concerned with their impression and public appearance to be more likely to lie, in order to maintain a socially desirable image. Kashy and DePaulo's (1996) diary study revealed that social desirability was linked to lying frequency. Visu-Petra, Miclea, Buş, and Visu-Petra (2014) also found that young adults with high impression management were more efficient in their deception (faster deceptive responses). By contrast, Gozna et al. (2001) did not find a significant relationship between lying and impression management.

Our study aimed to 1) track age differences in attitudes toward deception, and 2) investigate the relationship between attitudes, self-reported likelihood of lying, and the frequency of deception across a variety of hypothetical contexts. We were interested how individual differences in 3) anxiety and 4) social desirability are involved in the complex interplay between views toward deception and lying frequency as people age.

We painted an in-depth picture of attitudes toward deception by assessing perceptions of various types of lies: attitudes toward lies (white lies and degrees of lying) and the likelihood of approaching (prosocial and self-interested lies) or avoiding (risk of discovery or breaking a promise) different types of lies. We used the categories described by Lundquist et al. (2009) and administered Lundquist's questionnaire to subjects from four age groups, ranging from primary school to emerging adulthood. To our knowledge, few studies have examined both attitudes and deceptive behavior (Popliger et al., 2011; Talwar \& Lee, 2008), and none have related attitudes toward the likelihood of self-reported deceptive behavior across the maturation process.

We hypothesized that, across all age groups, more lenient attitudes toward deception would be associated with higher self-reported lying frequency.

To our knowledge, our work is the first to study a direct link between anxiety and people's view toward deception. We expected children and young adults with higher social anxiety to display less lenient views about deception, and a lower selfreported lying frequency. Additionally, we aimed to relate social desirability to attitudes toward deception and lying frequency, examining possible effects as people mature. We predicted that higher levels of self-reported social desirability would be linked to lower lie acceptability, and to a decreased frequency of self-reported lying. 


\section{Methods}

\section{Participants}

We included 177 Romanian participants from four different age groups: 46 primary school children, ages $7-11$ (Grades 1 to 4 ; mean age $=8.86$ years, $S D=1.09 ; 30$ boys); 41 middle school children, ages $11-15$ (Grades 5 to 8 ; mean age $=12.85$ years, $S D=1.39 ; 19$ boys); 49 high-school children, ages 15-19 (Grades 9 to 12; mean age $=17$ years, $S D=1.35 ; 17$ boys $)$; and 41 young adults $\left(2^{\text {nd }}\right.$ and $3^{\text {rd }}$ year students, mean age $=23.32$ years, $S D=5.62 ; 8$ men).

\section{Procedure}

First, we obtained formal consent from the children's parents or the participants themselves. A trained psychology student individually assessed participants during a single session.

\section{Questionnaires}

To measure participants' views about various types of lies, we adapted the questionnaire about attitudes toward deception developed by Lundquist et al. (2009). All items were expressed on a 4-point Likert scale (from strong disagreement to strong agreement). Two items measured attitudes toward white lies and degrees of lying. The other two items measured the self-reported likelihood of engaging in certain types of lies: prosocial or self-interested lies. Two items measured the likelihood of avoiding a certain type of deceptive behavior: related to risk of discovery, or having promised to tell the truth. Lastly, we assessed each participant's self-reported actual frequency of lying with one item on a 4-point Likert scale (never, once, sometimes, often).

We created two shorter versions of the questionnaire for the younger children in our sample. For lying frequency, we provided age-appropriate examples (see Appendix).

Next, the adults completed the impression management subscale of the Balanced Inventory of Desirable Responding (BIDR; Paulhus, 1991). To assess the children's social desirability, we administered the Children's Social Desirability Scale (CSD; Crandall, Crandall, \& Katkovsky, 1965). The children also completed the social anxiety subscale of the Revised Children's Anxiety and Depression Scale (Chorpita et al., 2000).

\section{Results}

Our first preliminary step was to test for gender differences on all outcomes, with an independent sample $t$-test. For middle school children, boys were more likely to avoid lying when they risked discovery $(M=2.89, S D=0.94)$ than girls $(M=2.19$, $S D=0.98): t(38)=-2.32, p<.05$. High-school girls reported greater social anxiety $(M=11.44, S D=4.63)$ than boys $(M=7.30, S D=3.29): t(47)=-3.27, p<.01$. Young adult women were more permissive toward white lies $(M=2.63, S D=.70)$ than men their age $(M=2.00, S D:=.76): t(39)=-2.28, p<.05)$, and also showed lower impression management $(M=6.33, S D=3.26)$ than men $(M=9.13, S D=3.64): t(39)=2.08$, $p<.05$, although for the adult group, these results might have been influenced by 
the disproportionately large number of women in our sample. Considering that its influence was limited to these variables, gender was omitted from the following analyses.

We performed a multivariate analysis of variance (MANOVA) to test for age differences in 1) attitudes toward white lies and 2) degrees of lying; in 3) engaging in prosocial and 4) self-interested lies; in 5) avoiding lies when risking discovery; and 6) in avoiding breaking a promise, as well as age differences in 7) self-reported lying frequency.

Across various types of lies, there was a significant multivariate effect of age: $F(3,172)=6.07, p=.001$, partial $\eta^{2}=.203$. Univariate tests with Bonferroni corrections showed a significant age effect for attitudes toward white lies $(F(3,172)=12.08$, $p=.001$, partial $\left.\eta^{2}=.180\right)$, but not toward degrees of lying $(F(3,172)=.33$, ns $)$. Bonferroni post hoc tests revealed that younger children in primary $(M=1.67 ; S D=.79)$ and middle school $(M=1.70 ; S D=.72)$ were less accepting of white lies than highschool children $(M=2.24 ; S D=.78)$ and young adults $(M=2.51 ; S D=.75)$.

There was also a univariate age effect for the likelihood of telling self-interested lies $\left(F(3,172)=4.17, p=.007\right.$, partial $\left.\eta^{2}=.068\right)$, but not for prosocial lies, $(F(3,172)=1.52, n s)$. Bonferroni post hoc tests showed that primary school children reported a lower tendency to tell self-interested lies $(M=1.48 ; S D=.89)$ than adults $(M=2.20 ; S D=.98)$

Univariate tests also revealed an age main effecton risk of discovery $\left(F(3,172)=6.33, p=.001\right.$, partial $\left.\eta^{2}=.099\right)$ and on promises to tell the truth $\left(F(3,173)=4.21, p=.007\right.$, partial $\left.\eta^{2}=.069\right)$. According to Bonferroni post hoc tests, middle school children $(M=2.53 ; S D=1.01)$ were less likely to avoid telling lies when they risked discovery, compared to primary school children $(M=3.24$; $S D=.97)$ and adults $(M=3.37 ; S D=.86)$. Middle school children also reported a lower tendency to avoid breaking a promise $(M=2.98 ; S D=.86)$ than adults $(M=3.61 ; S D=.63)$.

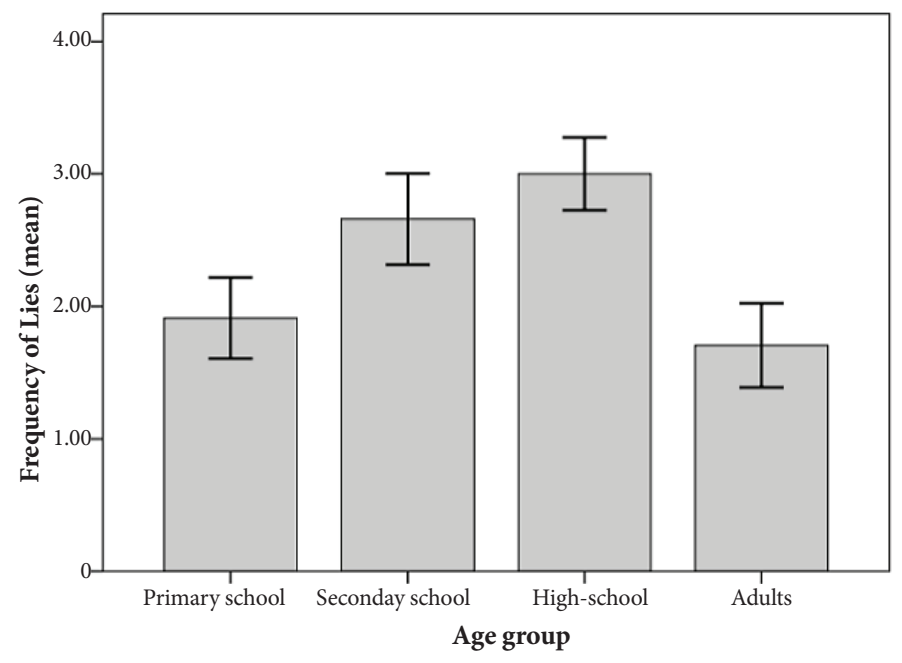

Figure 1. Self-reported frequency of lying according to age groups.

Note: Error bars: \pm 1 Standard errors

Lastly, we found a univariate age effect for self-reported frequency of lying: $F(3,172)=16.23 ; p=.001$, partial $\eta^{2}=.221$. Bonferroni post hoc tests showed that 
primary school children $(M=1.91 ; S D=1.03)$ and adults $(M=1.71 ; S D=1.01)$ reported lower frequencies than middle-school children $(M=2.68 ; S D=1.10)$ and high-school children $(M=3.00 ; S D=.96)$ (see Figure 1).

For the bivariate correlation results on the frequency of lying, attitudes toward deception, likelihood of deceit, social desirability (impression management in the adult sample), and social anxiety, see Table 1.

Table 1

Correlations between Attitudes, Likelihood of Lying, Frequency of Lying, Social Desirability, Impression Management \& Social Anxiety

\begin{tabular}{|c|c|c|c|c|c|c|c|c|c|c|c|}
\hline & \multicolumn{3}{|c|}{ Primary school } & \multicolumn{3}{|c|}{ Middle school } & \multicolumn{3}{|c|}{ High-school } & \multicolumn{2}{|c|}{ Young adults } \\
\hline & FL & SD & SA & FL & SD & SA & FL & SD & SA & FL & IM \\
\hline 1. White lies & .13 & -.15 & .03 & $.32^{*}$ & -.24 & -.05 & $.39^{* *}$ & -.20 & -.01 & .28 & $-.39^{\star}$ \\
\hline 2. Degrees of lying & -.12 & .10 & -.17 & .15 & -.15 & .09 & -.24 & -.15 & -.15 & -.09 & .27 \\
\hline 3. Prosocial lies & -.06 & -.20 & .06 & .10 & -.28 & $.46^{* *}$ & .06 & .02 & .07 & .04 & -.12 \\
\hline $\begin{array}{l}\text { 4. Self-interested } \\
\text { lies }\end{array}$ & .29 & -.08 & -.02 & .29 & -.24 & -.23 & $.28^{*}$ & -.27 & -.06 & $.31^{\star *}$ & $-.36^{*}$ \\
\hline 5. Risk of discovery & -.09 & -.25 & $.35^{\star}$ & .20 & -.28 & -.07 & .00 & -.02 & $.38^{\star *}$ & .30 & -.26 \\
\hline 6. Truth promise & $-.30^{*}$ & .12 & -.04 & .20 & .09 & -.07 & $-.28^{\star}$ & .16 & .15 & -.11 & .24 \\
\hline $\begin{array}{l}\text { 7. Frequency of } \\
\text { lying-typical lies }\end{array}$ & & $-.52^{\star *}$ & .27 & & $-.56^{\star *}$ & -.06 & & -.19 & -.16 & & $-.50^{\star *}$ \\
\hline
\end{tabular}

Note: ${ }^{*} p<.05 ;{ }^{* *} p<.01$

$F L=$ Frequency of lying; $S D=$ Social Desirability; $S A=$ Social Anxiety; $I M=$ Impression Management .

Table 2

Regression results predicting frequency of lying from age, social desirability, and deceptive attitudes measurements

\begin{tabular}{|c|c|c|c|c|c|}
\hline \multirow[b]{2}{*}{ Predictors } & \multicolumn{5}{|c|}{ Frequency of telling typical lies - all children $(N=136)$} \\
\hline & B & SE B & $\beta$ & $\Delta \mathrm{R}^{2}$ & Cumul. $\mathbf{R}^{2}$ \\
\hline \multicolumn{6}{|l|}{ Step 1 (enter method) } \\
\hline Age group & .01 & .09 & .01 & .00 & \\
\hline \multicolumn{6}{|l|}{ Step 2 (enter method) } \\
\hline Age group & -.33 & .08 & $-.32^{\star * *}$ & $.38^{\star \star *}$ & $.37^{\star * *}$ \\
\hline Social Desirability & -.08 & .01 & $-.69^{* * *}$ & & \\
\hline \multicolumn{6}{|l|}{ Step 3 (stepwise method) } \\
\hline Age group & -.38 & .08 & $-.37^{\star * *}$ & $.02^{*}$ & $.39^{\star *}$ \\
\hline Social Desirability & -.08 & .01 & $-.67^{\star *}$ & & \\
\hline Attitudes toward white lies & .22 & .10 & $.16^{*}$ & & \\
\hline Likelihood of telling prosocial lies & - & - & ns & & \\
\hline Likelihood of telling self-interested lies & - & - & ns & & \\
\hline
\end{tabular}

Note: ${ }^{* *} p<.001 ;{ }^{* *} p<.01 ;{ }^{*} p<.05$. 
Next, we performed two multiple regression analyses predicting self-reported lying frequency, one for children and adolescents $(N=136)$, and one for adults $(N=41)$. Two were necessary because the questions regarding lying frequency and the measurement for social desirability differed for children and adults. See Tables 2 and 3 for the regression results.

Table 3

Regression results predicting lying frequency from impression management and deceptive attitudes measurements

\begin{tabular}{|c|c|c|c|c|c|}
\hline \multirow[b]{2}{*}{ Predictors } & \multicolumn{5}{|c|}{ Frequency of telling typical lies - adults $(\mathrm{N}=41)$} \\
\hline & B & SE B & $\beta$ & $\Delta \mathbf{R}^{2}$ & Cumul. $\mathbf{R}^{2}$ \\
\hline \multicolumn{6}{|l|}{ Step 1 (enter method) } \\
\hline Impression management & -.14 & .16 & -.14 & .02 & .02 \\
\hline \multicolumn{6}{|l|}{ Step 2 (stepwise method) } \\
\hline Impression management & -.09 & .15 & -.09 & $.12^{*}$ & $.33^{\star *}$ \\
\hline Likelihood of telling prosocial lies & .38 & .17 & $.35^{* *}$ & & \\
\hline Attitudes toward white lies & - & - & ns & & \\
\hline Likelihood of telling self-interested lies & - & - & ns & & \\
\hline
\end{tabular}

Note: ${ }^{* *} p<.01 ;{ }^{*} p<.05$.

\section{Discussion}

Our main findings revealed that perceptions about deception change with age: younger children have more negative attitudes toward white lies and a decreased likelihood of telling self-interested lies than older children and adults. Regarding self-reported lying frequency, we found an inverted U-shape trend: primary-school children and adults display a lower frequency than middle-school children and high-schoolers. Additionally, we found gender variations for contextualized views about deception. From the perspective of individual differences, low anxiety was associated with a lower likelihood of telling prosocial lies and a lower likelihood of avoiding the risk of discovery. Reduced social desirability predicted a higher selfreported lying frequency.

Our investigation into specific views on deception uncovered a gradually nuanced acceptance of white lies, as adolescents and young adults became more accepting of white lies than younger children. This result is in line with previous studies (Talwar \& Crossman, 2011). Although young children can understand white lies and view them less negatively than self-interested lies (Bussey, 1999), the primary school children in our sample generally disagreed with white lies being a positive behavior $(84.8 \%$ of the sample, $n=39)$. Adolescents and young adults might have had more direct positive experiences with white lies, reinforcing their more lenient attitudes toward them.

Primary school children were less likely to tell self-interested lies compared to young adults. Although people become more averse to selfish lies with age (Jensen et al., 2004; Popliger et al., 2011), the self-interested lies expressed in our questionnaire involved increased personal gain for the liar at no cost for the receiver (as opposed to antisocial lies, for instance), which offers a plausible explanation for our 
results. The propensity to lie increases with personal gain, and decreases the more others stand to lose (Gneezy, 2005; Lundquist et al., 2009), which is why this type of lie appears more acceptable to adults. Young primary school children might have not gained enough social experience to understand this distinction.

We found no age differences in the likelihood of prosocial lies. In fact, participants from all age groups were unlikely to tell this type of lie. This might be because the prosocial lies included in our questionnaire involved helping others at a personal cost. Talwar et al. (2016) showed that older primary school children gave a positive rating to prosocial lies which involved costs to themselves and were less likely to condemn them than younger children.

Middle school children showed less aversion to lies with a risk of discovery than primary school children, or adults. Increases in reward-seeking behavior, coupled with greater impulsivity, might make younger school-age children more prone to risk-taking than older children and adults (Steinberg, 2010). At the same time, middle-school children had a lower aversion to breaking a promise than adults; however, they were still unlikely to break the promise. Consistently, Talwar, Lee, Bala, and Lindsay (2004) found that children who promised to tell the truth were less likely to lie afterwards. Our study suggests that an explicit promise of honesty leads to a strong aversion to lying, even in the case of younger children. This has implied applications, such as confirming that legal procedures should involve asking children to promise to tell the truth before testifying in court, in order to minimize the risk of deceptive behavior.

We found a significant age effect on self-reported frequency of lying; primary school children and adults reported fewer lies than middle-school and high-schoolers. Lying increased from young childhood, reached a peak in adolescence, and then decreased for young adults, which supports the developmental trajectory from other studies (Debey et al., 2015; Lavoie et al., 2017; Talwar \& Crossman, 2011).

Furthermore, our findings suggest a connection between perceptions of deception and self-reported frequency of lying, confirming previous literature on adults (Brasher et al., 2014; Halevy et al., 2014; Serota et al., 2012). Children and adolescents displayed more lenient attitudes toward white lies, and this predicted higher self-reported lie-telling, independent of age effects. For adults, a greater likelihood of telling prosocial lies predicted higher self-reported lying frequency. It is plausible that, with age, attitudes toward lies become more lenient, and this increase in acceptance leads to a higher propensity toward lying. Our results suggest that the acceptability and the context of deception might be involved in determining a person's lie-telling behavior, a deeper knowledge of this phenomenon could aid educational and parental practices for promoting honest behavior.

Our results also revealed limited evidence of gender differences for attitudes toward deception. Middle school girls were more likely to tell lies despite the risk of discovery, and young adult women were more permissive of white lies. Our findings were consistent with other self-report studies (Ning \& Crossman, 2007). Also, these gender differences might have appeared because the young women in our sample displayed lower social desirability, thus being more likely to report permissive attitudes toward deception.

From the perspective of individual differences, we found that reduced social anxiety was related to a decreased likelihood of engaging in prosocial lies, as well as with a lower likelihood of avoiding lies with a risk of discovery. These results 
are the first to suggest that anxiety plays a role in children's attitude toward deception; this is congruent with studies linking adults' anxiety with deceptive behavior (Caso et al., 2005; Eswara \& Suryarekha, 1974). Children with low social anxiety might be less likely to avoid discovery when lying because of their lower behavioral inhibition (Gest, 1997; Muris, \& Meesters, 2002), and being more inclined to take risks (Steinberg, 2010). Then again, lower anxiety might mean individuals are more comfortable with lying, feeling less fear and guilt.

Regarding social desirability, lower impression management in young adults was related to their higher acceptance of white lies and the increased likelihood of telling self-interested lies. Children's lower social desirability predicted higher self-reported lying frequency. Our results showed that socially desirable responses are related to attitudes toward deception and lying frequency; this expands the results of previous research (Kashy \& DePaulo, 1996; Visu-Petra et al., 2014). Children and adolescents who are less concerned with the impression they make on others might be more likely to admit to lying. Impression management did not predict lying frequency in young adults; but this may have been because of the different measurement used.

\section{Conclusion}

Our work extends previous designs by offering an integrative view into people's attitudes toward deception and their self-reported lying throughout their maturation process. Attitudes toward white lies (by children and adolescents) and the self-reported likelihood of prosocial lies (by young adults) were the most relevant predictors of self-reported lie-telling. Children with decreased anxiety were less likely to tell prosocial lies, implying that anxiety might be a key factor in children's development of deception. Individual differences in social desirability were also relevant; although they might resort to lie-telling, children with increased social desirability might under-report their behavior to manage their social image and impression on others.

\section{Limitations}

Our study has several limitations. For example, self-report measures might not be the best avenue to discovering people's implicit attitudes and lie-telling, and yet we relied on previous studies that correlated self-reported frequency of lying and reallife deception (Brasher et al., 2014; Halevy et al, 2014; Oliveira \& Levine, 2008). Perhaps younger children found it difficult to report their deceptive behavior and beliefs. However, young children are able to admit to telling lies (Talwar \& Lee, 2008), and all participants were evaluated by a trained psychology student. Additionally, to assess all participants in an age-appropriate manner, we used different measures of social desirability for children and adults.

\section{Acknowledgements}

This work was supported by the Romanian National Authority for Scientific Research, CNCS - UEFISCDI, under Grants PNI-II- RU-TE-2012-3-0323 and PNIII-P1-1.1-TE 2016-2170 as well as a Developing Country Fellowship awarded to the last author by the International Society for the Study of Behavioural Development. We thank Andreea Nariţa and Oana Maria Rognean for their assistance with data collection. 


\section{References}

Brasher, M., Lee, S., Shather, B., \& Mou, Q. (2014). The Slippery Slope: The Effects of Lying on Lie Acceptability. Murray State University Explorations Journal. Retrieved from https://sites.google.com/a/murraystate.edu/graduate-journal/home

Bussey, K. (1999). Children's Categorization and Evaluation of Different Types of Lies and Truths. Child Development, 70(6), 1338-1347. https://doi.org/10.1111/1467-8624.00098

Caso, L., Gnisci, A., Vrij, A., \& Mann, S. (2005). Processes Underlying Deception: an Empirical Analysis of Truth and Lies when Manipulating the Stakes. Journal of Investigative Psychology and Offender Profiling, 2(3), 195-202. https://doi.org/10.1002/jip.32

Chorpita, B.F., Yim, L., Moffitt, C., Umemoto, L.A., \& Francis, S.E. (2000). Assessment of Symptoms of DSM-IV Anxiety and Depression in Children: A Revised Child Anxiety and Depression Scale. Behavior Research and Therapy, 38(8), 835-855. https://doi.org/10.1016/S0005-7967(99)00130-8

Crandall, V.C., Crandall, V.J., \& Katkovsky, W. (1965). A Children's Social Desirability Questionnaire. Journal of Consulting Psychology, 29(1), 27. https://doi.org/10.1037/h0020966

Debey, E., De Schryver, M., Logan, G.D., Suchotzki, K., \& Verschuere, B. (2015). From Junior to Senior Pinocchio: A Cross-sectional Lifespan Investigation of Deception. Acta Psychologica, 160, 58-68. https://doi.org/10.1016/j.actpsy.2015.06.007

DePaulo, B.M., Ansfield, M.E., Kirkendol, S.E., \& Boden, J.M. (2004). Serious Lies. Basic and Applied Social Psychology, 26(2-3), 147-167. https://doi.org/10.1080/01973533.2004.9646402

Eswara, H.S., \& Suryarekha, A. (1974). The Relationship between Lie Scores and Anxiety Scores on Taylor's Manifest Anxiety Scale. Journal of Psychological Research, 18(3), 88-90.

Gest, S.D. (1997). Behavioral Inhibition: Stability and Associations with Adaptation from Childhood to Early Adulthood. Journal of Personality and Social Psychology, 72(2), 467. https://doi.org/10.1037/0022-3514.72.2.467

Glätzle-Rützler, D., \& Lergetporer, P. (2015). Lying and Age: An Experimental Study. Journal of Economic Psychology, 46, 12-25. https://doi.org/10.1016/j.joep.2014.11.002

Gneezy, U. (2005). Deception: The Role of Consequences. American Economic Review, 95(1), 384394. https://doi.org/10.1257/0002828053828662

Goosie, M.S. (2014). An Investigation into the Shift in Lie Acceptability in Children from Grades 3-12 (Master's Thesis). Retrieved from http://dc.etsu.edu/etd/2376/

Gozna, L.F., Vrij, A., \& Bull, R. (2001). The Impact of Individual Differences on Perceptions of Lying in Everyday Life and in a High Stake Situation. Personality and Individual Differences, 31(7), 1203-1216. https://doi.org/10.1016/S0191-8869(00)00219-1

Halevy, R., Shalvi, S., \& Verschuere, B. (2014). Being Honest About Dishonesty: Correlating Self-Reports and Actual Lying. Human Communication Research, 40(1), 54-72. https://doi.org/10.1111/hcre.12019

Jensen, L.A., Arnett, J.J., Feldman, S.S., \& Cauffman, E. (2004). The Right to Do Wrong: Lying to Parents among Adolescents and Emerging adults. Journal of Youth and Adolescence, 33(2), 101-112. https://doi.org/10.1023/B:JOYO.0000013422.48100.5a

Kashy, D.A., \& DePaulo, B.M. (1996). Who Lies? Journal of Personality and Social Psychology, 70(5), 1037-1051. https://doi.org/10.1037/0022-3514.70.5.1037

Lavoie, J., Nagar, P.M., \& Talwar, V. (2017). From Kantian to Machiavellian Deceivers: Development of Children's Reasoning and Self-reported Use of Secrets and Lies. Childhood, 24(2), 197-211. https://doi.org/10.1177/0907568216671179

Levine, T.R., McCornack, S.A., \& Avery, P.B. (1992). Sex Differences in Emotional Reactions to Discovered Deception. Communication Quarterly, 40(3), 289-296. https://doi.org/10.1080/01463379209369843

Levine, T.R., Serota, K.B., Carey, F., \& Messer, D. (2013). Teenagers Lie a Lot: A Further Investigation into the Prevalence of Lying. Communication Research Reports, 30(3), 211-220. https://doi.org/10.1080/08824096.2013.806254

Lundquist, T., Ellingsen, T., Gribbe, E., \& Johannesson, M. (2009). The Aversion to Lying. Journal of Economic Behavior \& Organization, 70(1), 81-92. https://doi.org/10.1016/j.jebo.2009.02.010 
Maggian, V., \& Villeval, M.C. (2013). Social Preferences and Lying Aversion in Children. https://doi.org/10.2139/ssrn.2368098

McLeod, B.A., \& Genereux, R.L. (2008). Predicting the Acceptability and Likelihood of Lying: The Interaction of Personality with Type of Lie. Personality and Individual Differences, 45(7), 591-596. https://doi.org/10.1016/j.paid.2008.06.015

Muris, P., \& Meesters, C. (2002). Attachment, Behavioral Inhibition, and Anxiety Disorders Symptoms in Normal Adolescents. Journal of Psychopathology and Behavioral Assessment, 24(2), 97-106. https://doi.org/10.1023/A:1015388724539

Ning, S.R., \& Crossman, A.M. (2007). We Believe in Being Honest: Examining Subcultural Differences in the Acceptability of Deception. Journal of Applied Social Psychology, 37(9), 2130-2155. https://doi.org/10.1111/j.1559-1816.2007.00254.x

Oliveira, C.M., \& Levine, T.R. (2008). Lie Acceptability: A Construct and Measure. Communication Research Reports, 25(4), 282-288. https://doi.org/10.1080/08824090802440170

Paulhus, D.L. (1991). Measurement and Control of Response Bias. In J.P. Robinson, P.R. Shaver, L.S. Wrightsman (Eds.), Measures of personality and social psychological attitudes, Vol. 1. (pp. 17-59). San Diego, CA, US: Academic Press. https://doi.org/10.1016/B978-0-12-590241-0.50006-X

Popliger, M., Talwar, V., \& Crossman, A. (2011). Predictors of Children's Prosocial Lie-telling: Motivation, Socialization Variables, and Moral Understanding. Journal of Experimental Child Psycho$\log y$, 110(3), 373-392. https://doi.org/10.1016/j.jecp.2011.05.003

Serota, K.B., Levine, T.R. and Boster, F.J. (2010). The Prevalence of Lying in America: Three Studies of Self-Reported Lies. Human Communication Research, 36, 2-25. https://doi.org/10.1111/j.1468-2958.2009.01366.x

Serota, K.B., Levine, T.R., \& Burns, A. (2012). A few prolific liars: Variation in the prevalence of lying. Proceedings from the 98th Annual Convention of the National Communication Association. Orlando, Florida.

Steinberg, L. (2010). A Dual Systems Model of Adolescent Risk-Taking. Developmental Psychobiology, 52(3), 216-224. https://doi.org/10.1002/dev.20445

Talwar, V., \& Crossman, A. (2011). From Little White Lies to Filthy Liars: The Evolution of Honesty and Deception in Young Children. Advances in Child Development and Behavior, 40, 140. https://doi.org/10.1016/B978-0-12-386491-8.00004-9

Talwar, V., \& Lee, K. (2008). Social and Cognitive Correlates of Children's Lying Behavior. Child Development, 79(4), 866-881. https://doi.org/10.1111/j.1467-8624.2008.01164.x

Talwar, V., Lee, K., Bala, N., \& Lindsay, R.C.L. (2004). Children's Lie-Telling to Conceal a Parent's Transgression: Legal Implications. Law and Human Behavior, 28(4), 411-435. https://doi.org/10.1023/B:LAHU.0000039333.51399.f6

Talwar, V., Murphy, S.M., \& Lee, K. (2007). White Lie-Telling in Children for Politeness Purposes. International Journal of Behavioral Development, 31(1), 1-11. https://doi.org/10.1177/0165025406073530

Talwar, V., Williams, S.M., Renaud, S.J., Arruda, C., \& Saykaly, C. (2016). Children's Evaluations of Tattles, Confessions, Prosocial and Antisocial Lies. International Review of Pragmatics, 8(2), 334-352. https://doi.org/10.1163/18773109-00802007

Visu-Petra, G., Miclea, M., Buş, I., \& Visu-Petra, L. (2014). Detecting Concealed Information: The Role of Individual Differences in Executive Functions and Social Desirability. Psychology, Crime \& Law, 20(1), 20-36. https://doi.org/10.1080/1068316X.2012.736509

Original manuscript received November 25, 2019

Revised manuscript accepted December 24, 2019 First published online March 15, 2020

To cite this article: Buta, M., Visu-Petra, G., Koller, S.H., Visu-Petra, L. (2020). A Little Lie Never Hurt Anyone: Attitudes toward Various Types of Lies over the Lifespan. Psychology in Russia: State of the Art, 13(1), 70-81. DOI: 10.11621/pir.2020.0107 


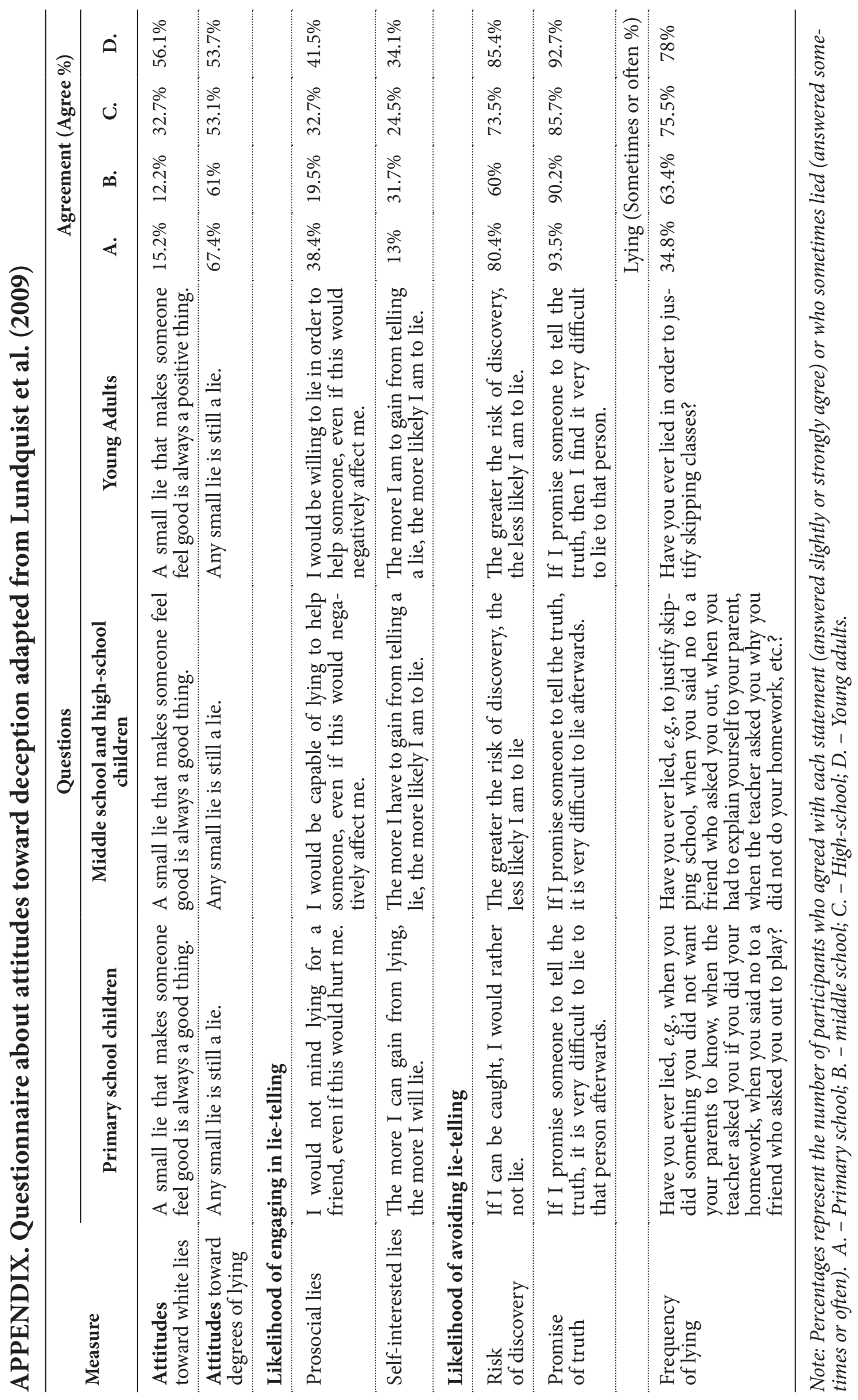

